Полищук Елена Анатольевна

кандидат экономических наук, доцент, доцент кафедры менеджмента предпринимательской деятельности Института экономики и управления Крымского федерального университета имени В.И. Вернадского

\section{СЦЕНАРНОЕ ПРОГНОЗИРОВАНИЕ РАЗВИТИЯ ИНДИКАТОРОВ РЫНКА ТРУДА МОЛОДЕЖИ В УСЛОВИЯХ ТРАНСФОРМАЦИОННЫХ ПРЕОБРАЗОВАНИЙ} (НА ПРИМЕРЕ РЕСПУБЛИКИ КРЫМ)

\section{Аннотация:}

В рамках исследования проведено сценарное прогнозирование развития главных индикаторов рынка труда молодежи Крыма в условиях трансформационных преобразований. Выделены особенности ос новных вариантов сценариев (консервативного, модернизационного и инновационного), на базе которых рассчитаны значения индикаторов с учетом параметров плана реализации Стратегии соци ально-экономического развития Республики Крым до 2030 г. Развитие рынка труда молодежи при модернизационном сценарии позволит нивелировать существующие ограничения, что поспособствует активному введению регулятивных мер в рассматриваемую сферу и переходу на инновационный сиенарий развития. Сделан вывод, что сценарный подход рекомендуется для использования в процессе регулирования рынка труда молодежи. Он дает возможность экспериментировать с проектами осуществления ключевых разработок в режиме реального времени, пошагово корректировать плань действий, оценивать последствия их внедрения до реализации на практике не только ответственным исполнителям и соисполнителям, но и каждому участнику анализируемого рынка.

Ключевые слова:

молодежь, рынок труда, трансформационные преобразования, индикатор, сценарный подход, сценарий, прогнозирование, социально-экономиче ский рост.

\section{Polishchuk Elena Anatolyevna}

PhD in Economics, Associate Professor Business Management Department Institute of Economics and Management V.I. Vernadsky Crimean Federal University

\section{SCENARIO PLANNING OF THE YOUTH LABOR MARKET INDICATORS DEVELOPMENT IN THE TRANSFORMATIONAL CONTEXT (A CASE OF THE REPUBLIC OF CRIMEA)}

Summary

The study presents the scenario planning of the basic indicators development of the youth labor market in the Republic of Crimea in the context of transformations. The aspects of the main possible scenarios (conservative, modernization and innovative) are highlighted. They serve as the basis for analyzing the youth labor market indicators considering the implementation plan properties of the Strategy for Social and Economic Development of the Republic of Crimea to 2030. The de velopment of the youth labor market within the modernization scenario will reduce the existing restrictions that will dynamically introduce the regulatory measures to the field under review and allow one to transit to an innovative development scenario. The author concludes that the scenario approach can be used while regulating the youth labor market. Scenario planning allows not only responsible executors and co-executors but also every party to market under review to test the real-time key project contents, adjust scenario step-by step, assess the possible impacts of projects until their implementation.

Keywords youth, labor market, transformations, indicator, scenario approach, scenario, planning, social and economic growth.

Введение. Принятие в начале 2017 г. закона «О стратегии социально-экономического развития Республики Крым до 2030 г.» (далее - Стратегия) [1] повлияло на изменение инструментальной направленности регулирования не только рынка труда в целом, но и его значимых сегментов. В частности, речь идет о рынке труда молодежи, формирующем условия рационального использования рабочей силы представителей молодого поколения, в качестве важной компоненты в реализации стратегического развития региона.

Целесообразность разработки Стратегии обусловлена необходимостью оценки изменений в пространстве и времени, своевременного обнаружения рисков и принятия мер, влияющих на минимизацию ущерба. Из этого вытекает актуальность определения возможных масштабов прогнозирования в условиях неопределенности последствий исполнения решений, так как именно прогноз позволяет выявить и изучить подобные риски, учесть комплекс сценариев, траекторий развития, выбрать оптимальный вариант из всех возможных альтернатив.

Цель исследования заключается в осуществлении сценарного прогнозирования развития основных индикаторов рынка труда молодежи в условиях преобразований, происходящих в Республике Крым. 
В рамках экономического прогнозирования одним из оптимальных с теоретической и практической точек зрения считается сценарный подход, достаточно известный в научных исследованиях [2]. Он позволяет проектировать всевозможные варианты развития социально-экономических явлений, в нашем случае рынка труда молодежи, при обоснованном анализе каждого из них. C его помощью можно отслеживать наиболее вероятные направления в целях прогнозирования всех допустимых перспектив и выбора подходящего сценария (траектории) развития.

Результаты исследования и их обсуждение. Существуют различные сценарные варианты, способствующие развитию социально-экономических систем, в частности рынка труда (пессимистичный, стабильный, оптимистичный, инерционный, инновационный, ускоренный, консервативный, инвестиционный и др.) [3]. При этом выделение одного из них остается весьма субъективным.

В настоящем исследовании мы опираемся на заданные в Стратегии сценарии [4]: консервативный (кризисный, стрессовый), модернизационный и инновационный, построенные на основе данных ведущих экспертов с учетом ретроспективной оценки базовых показателей социального и экономического развития республики (рисунок 1).

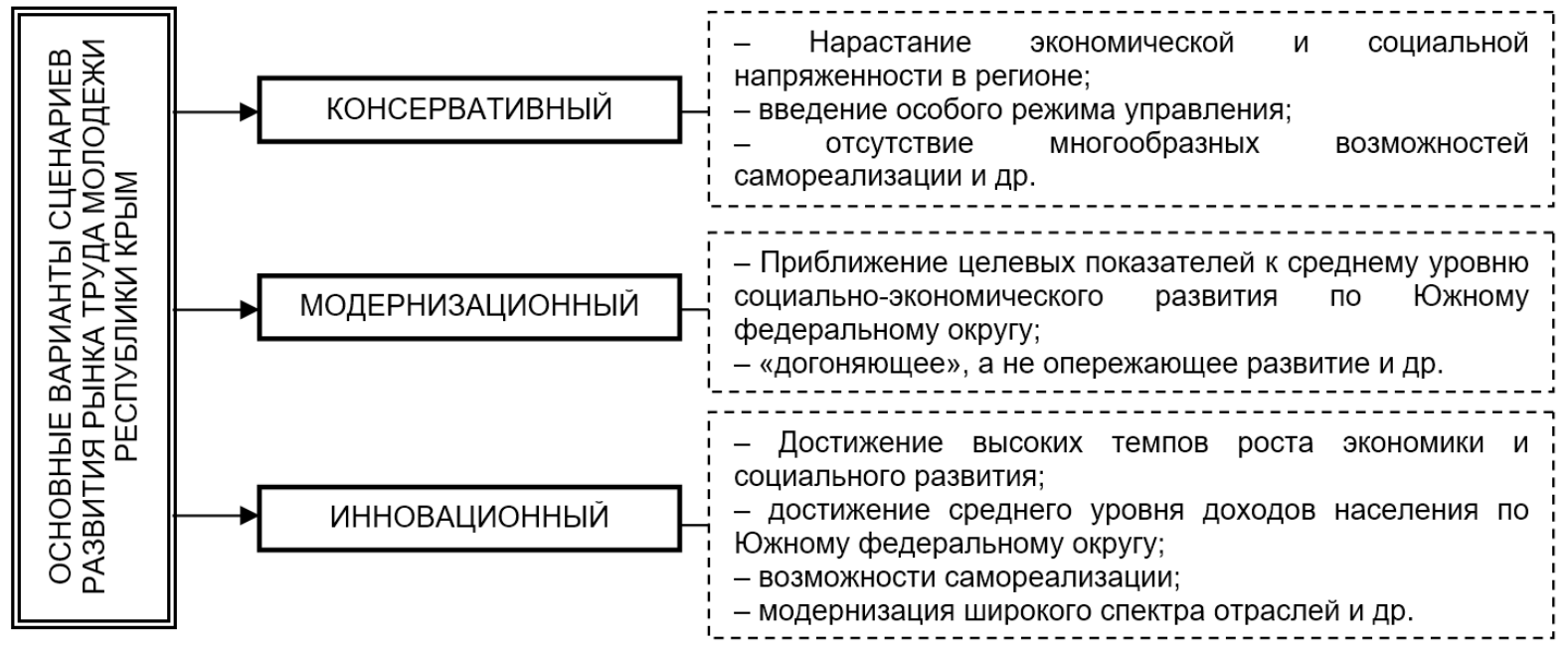

Рисунок 1 - Особенности основных вариантов сценариев согласно Стратегии до 2030 г.

Отметим, что в рамках исследования уровень молодежной безработицы (по методологии MOT) является сценарным параметром, при этом в качестве базисного периода приняты данные 2017 г. Представим сценарные значения результирующих индикаторов (таблица 1):

- 1-й сценарий - консервативный - предусматривает ежегодное увеличение уровня молодежной безработицы на 1,5\%;

- 2-й сценарий - модернизационный - уровень молодежной безработицы предполагается не ниже базового значения 2017 г. с возможным ежегодным снижением на 0,3 \%, что в среднем соответствует уровню Южного федерального округа [5], в состав которого входит регион;

- 3-й сценарий - инновационный - ежегодное сокращение уровня молодежной безработицы на 2,0\%.

Таблица 1 - Сценарные условия изменения уровня молодежной безработицы (по методологии МОТ) в период с 2018 по 2026 г., \%

\begin{tabular}{|l|c|c|c|c|}
\hline \multirow{2}{*}{ Сценарий } & \multicolumn{4}{|c|}{ Год } \\
\cline { 2 - 5 } & $\mathbf{2 0 1 8}$ & $\mathbf{2 0 1 9}$ & $\mathbf{2 0 2 0}$ & $\mathbf{2 0 2 6}$ \\
\hline Консервативный $(1-\bar{и})$ & 15,0 & 16,5 & 18,0 & 27,0 \\
\hline Модернизационный $(2-\breve{и})$ & 13,2 & 12,9 & 12,6 & 10,8 \\
\hline Инновационный (3-й) & 12,7 & 10,7 & 8,7 & 2,7 \\
\hline
\end{tabular}

При помощи «проигрывания» выделенных сценариев представлен прогноз индикаторов рассматриваемого рынка, проведена сравнительная характеристика рассчитанных значений с пороговыми и прогнозными, сделаны выводы о наличии (отсутствии) явных угроз. Результаты прогнозирования индикаторов рынка труда молодежи на основе применения регрессионных моделей согласно консервативному, модернизационному и инновационному вариантам сценарных условий приведены в таблице 2. 
Таблица 2 - Результаты прогнозирования основных индикаторов рынка труда молодежи согласно вариантам сценариев

\begin{tabular}{|c|c|c|c|c|c|}
\hline \multirow{2}{*}{ Индикатор } & \multirow{2}{*}{\begin{tabular}{|l|} 
Отчет \\
2017 \\
\end{tabular}} & \multicolumn{4}{|c|}{ Прогноз } \\
\hline & & \multicolumn{4}{|c|}{\begin{tabular}{c|c}
\multicolumn{2}{|c}{ Прогноз } \\
2019 & 2020
\end{tabular}} \\
\hline \multicolumn{6}{|l|}{ Консервативный сценарий } \\
\hline Уровень молодежной безработицы (по методологии МОТ), \% & 13,5 & 15,0 & 16,5 & 18,0 & 27,0 \\
\hline Уровень занятости молодежи, \% & 59,7 & 57,4 & 55,4 & 53,3 & 41,2 \\
\hline Уровень регистрируемой молодежной безработицы, \% & 2,3 & 2,9 & 3,5 & 4,1 & 7,8 \\
\hline Коэффиициент напряженности на рынке труда молодежи, ед. & 3,2 & 3,9 & 4,8 & 5,7 & 10,8 \\
\hline Коэффицциент реального трудоустройства молодежи, ед. & 0,72 & 0,67 & 0,62 & 0,57 & 0,25 \\
\hline $\begin{array}{l}\text { Коэфффициент трудоустройства представителей молодежи из числа по- } \\
\text { лучивших услуги, содействующие повышению уровня конкурентоспо- } \\
\text { собности, ед. }\end{array}$ & 0,39 & 0,34 & 0,30 & 0,26 & 0,05 \\
\hline \multicolumn{6}{|l|}{ Модернизационный сценарий } \\
\hline Уровень молодежной безработицы (по методологии МОТ), \% & 13,5 & 13,2 & 12,9 & 12,6 & 10,8 \\
\hline Уровень занятости молодежи, \% & 59,7 & 59,8 & 60,2 & 60,6 & 63,0 \\
\hline Уровень регистрируемой молодежной безработицы, \% & 2,3 & 2,2 & 2,1 & 1,9 & 1,2 \\
\hline Коэфффициент напряженности на рынке труда молодежи, ед. & 3,2 & 2,9 & 2,7 & 2,6 & 1,5 \\
\hline Коэфффициент реального трудоустройства молодежи, ед. & 0,72 & 0,73 & 0,74 & 0,75 & 0,80 \\
\hline $\begin{array}{l}\text { Коэфффициент трудоустройства представителей молодежи из числа по- } \\
\text { лучивших услуги, содействующие повышению уровня конкурентоспо- } \\
\text { собности, ед. }\end{array}$ & 0,39 & 0,41 & 0,44 & 0,46 & 0,60 \\
\hline \multicolumn{6}{|l|}{ Инновационный сценарий } \\
\hline Уровень молодежной безработицы (по методологии МОТ), \% & 13,5 & 12,7 & 10,7 & 8,7 & 2,7 \\
\hline Уровень занятости молодежи, \% & 59,7 & 60,5 & 63,2 & 65,9 & 74,0 \\
\hline Уровень регистрируемой молодежной безработицы, \% & 2,3 & 1,9 & 1,4 & 0,8 & 0,1 \\
\hline Коэфффициент напряженности на рынке труда молодежи, ед. & 3,2 & 2,8 & 2,4 & 2,0 & 0,3 \\
\hline Коэфффициент реального трудоустройства молодежи, ед. & 0,72 & 0,75 & 0,82 & 0,89 & 1,00 \\
\hline $\begin{array}{l}\text { Коэфффициент трудоустройства представителей молодежи из числа по- } \\
\text { лучивших услуги, содействующие повышению уровня конкурентоспо- } \\
\text { собности, ед. }\end{array}$ & 0,39 & 0,45 & 0,60 & 0,75 & 1,00 \\
\hline
\end{tabular}

Анализ данных таблицы 2 позволяет заключить следующее.

- Реализация консервативного сценария отражает наихудший вариант развития рынка труда молодежи, при котором все протекающие процессы отрицательно сказываются на изменениях анализируемых индикаторов. В современных условиях вероятность его наступления значительно снизилась по причине активного выполнения ряда государственных программ и подпрограмм Республики Крым, положительно влияющих на рынок труда, о чем свидетельствуют значения отдельных показателей в базисном периоде.

- Инновационный сценарий осуществим только в условиях высоких темпов роста экономики Республики Крым до 2026 г. Однако по результатам исследования можно предположить, что его реализация до 2026 г. не представляется возможной из-за недостаточного потенциала развития региона.

- Наиболее вероятным для исполнения выступает модернизационный сценарий, основанием которого является достижение значений анализируемых индикаторов уровня Южного федерального округа, что обусловлено сформировавшимися тенденциями развития регионального рынка труда (таблица 3).

Таблица 3 - Значения индикаторов рынка труда молодежи с учетом плана реализации Стратегии развития согласно модернизационному сценарию

\begin{tabular}{|c|c|c|c|c|c|c|c|}
\hline \multirow[t]{2}{*}{ Индикатор } & 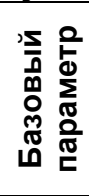 & 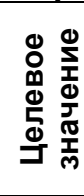 & 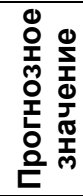 & \multirow[t]{2}{*}{ 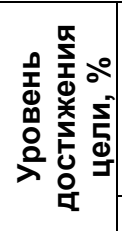 } & 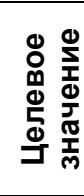 & 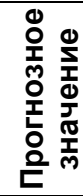 & \multirow[t]{2}{*}{ 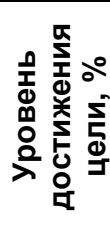 } \\
\hline & 2018 & 2020 & 2020 & & 2026 & 2026 & \\
\hline $\begin{array}{l}\text { Уровень молодежной безработицы (по методологии } \\
\text { МОТ), \% }\end{array}$ & 13,5 & 12,0 & 12,6 & 95 & 10,0 & 10,8 & 93 \\
\hline Уровень занятости молодежи, \% & 59,7 & 60,0 & 60,6 & 101 & 60,0 & 63,0 & 105 \\
\hline Уровень регистрируемой молодежной безработицы, \% & 2,3 & 2,0 & 1,9 & 105 & 2,0 & 1,2 & 166 \\
\hline $\begin{array}{l}\text { Коэфффициент напряженности на рынке труда моло- } \\
\text { дежи, ед. }\end{array}$ & 3,2 & 3,0 & 2,6 & 115 & 2,0 & 1,5 & 133 \\
\hline Коэфффициент реального трудоустройства молодежи, ед. & 0,72 & 0,75 & 0,75 & 100 & 0,80 & 0,80 & 100 \\
\hline $\begin{array}{l}\text { Коэффрициент трудоустройства представителей моло- } \\
\text { дежи из числа получивших услуги, содействующие по- } \\
\text { вышению уровня конкурентоспособности, ед. }\end{array}$ & 0,39 & 0,42 & 0,46 & 109 & 0,70 & 0,60 & 86 \\
\hline
\end{tabular}


В соответствии с приведенной в таблице 3 информацией можно заключить, что развитие рынка труда молодежи в рамках модернизационного сценария позволит нивелировать существующие ограничения. Это поспособствует активной реализации необходимых мероприятий и переходу на инновационный сценарий развития, ожидаемыми результатами осуществления которого являются устойчивое развитие республики, включая повышение уровня качества жизни (благосостояния) населения, в особенности представителей молодежи, укрепление их образовательного, трудового, культурно-бытового потенциала.

Заключение. Применяемый подход рекомендуется для использования при регулировании рынка труда молодежи. Механизм позволит экспериментировать со сценариями внедрения ключевых разработок в режиме реального времени и даст возможность не только ответственным исполнителям и соисполнителям, но и каждому участнику анализируемого рынка пошагово корректировать планы, оценивать последствия их осуществления до реализации на практике.

\section{Ссылки и примечания:}

1. О стратегии социально-экономического развития Республики Крым до 2030 г. [Электронный ресурс] : закон Республики Крым от 9 янв. 2017 г. № 352-3РК/2017 // Правительство Республики Крым : официальный портал. URL: https://rk.gov.ru/rus/file/pub/pub_322716.pdf (дата обращения: 06.08.2018).

2. Васильева А.В., Тарасьев А.А. Прогноз развития миграционных процессов и рынка труда в регионах России // Экономика региона. 2014. № 4. С. 283-298 ; Ибрагимова 3.Ф. Сценарный подход в прогнозировании уровня бедности населения в Российской Федерации // Общество: политика, экономика, право. 2018. № 1. С. 39-43. https://doi.org/10.24158/pep.2018.1.6 ; Молчанова М.Ю., Печенкина А.В. Применение сценарного метода при прогнозировании ситуации на рынке жилья г. Перми // Вестник Пермского университета. Сер.: Экономика. 2015. № 1 (24). С. 79-88; Патракеева О.Ю. Применение имитационного моделирования и сценарного подхода к анализу экономики приграничных регионов // Вестник Южного научного центра. 2015. T. 11, № 4. C. 69-76 ; Rowland N.J., Spaniol M.J. Social foundation of scenario planning // Technological forecasting and social change. 2017. No. 124. P. 6-15. https://doi.org/10.1016/j.techfore.2017.02.013.

3. Васильева А.В., Тарасьев А.А. Указ. соч. ; Ибрагимова З.Ф. Указ. соч. ; Колосова О.Г. Рынок труда специалистов в условиях реализации инвестиционных проектов // Вестник Омского университета. Сер.: Экономика. 2014. № 1. С. 4348 ; Молчанова М.Ю., Печенкина А.В. Указ. соч. ; Патракеева О.Ю. Указ. соч. ; Scenarios and their application in strategic planning / E. Vacík, J. Fotr, M. Špaček, I. Souček // Economics and Management. 2014. No. 17 (3). P. 118-135. https://doi.org/10.15240/tul/001/2014-3-010

4. О стратегии ...

5. Рабочая сила, занятость и безработица в России (по результатам выборочных обследований рабочей силы). 2016 [Электронный ресурс] : статистический сборник // Федеральная служба государственной статистики : официальный сайт. 2016. URL: http://www.gks.ru/bgd/regl/B16_61/Main.htm (дата обращения: 06.08.2018).

\section{References:}

Ibragimova, ZF 2018, 'Scenario approach to predict the poverty rate in the Russian Federation', Obshchestvo: politika, ekonomika, pravo, no. 1, pp. 39-43. https://doi.org/10.24158/pep.2018.1.6

Kolosova, OG 2014, 'Labor market specialists while implementing the investment projects', Vestnik Omskogo universiteta. Ser.: Ekonomika, no. 1, pp. 43-48, (in Russian).

Molchanova, MYu \& Pechenkina, AV 2015, 'Application of the scenario method in forecasting the situation in the housing market in Perm', Vestnik Permskogo universiteta. Ser.: Ekonomika, no. 1 (24), pp. 79-88, (in Russian).

Patrakeeva, OYu 2015, 'The use of simulation modeling and scenario approach to analyze the economy of border regions', Vestnik Yuzhnogo nauchnogo tsentra, vol. 11, no. 4, pp. 69-76, (in Russian).

Rowland, NJ \& Spaniol, MJ 2017, 'Social foundation of scenario planning', Technological forecasting and social change, no. 124, pp. 6-15. https://doi.org/10.1016/j.techfore.2017.02.013.

Vacík, E, Fotr, J, Špaček, M \& Souček, I 2014, 'Scenarios and their application in strategic planning', Economics and Management, no. 17 (3), pp. 118-135. https://doi.org/10.15240/tul/001/2014-3-010.

Vasilyeva, AV \& Tarasyev, AA 2014, 'Forecast of the migration processes development and the labor market in the Russian regions', Ekonomika regiona, no. 4, pp. 283-298, (in Russian). 